\title{
Dearborn SHINES During the COVID-19 Pandemic: Youth Experiences and Outcomes With Virtual Physical Activity and Healthy Eating Programming
}

\author{
Jeanne Barcelona Erin Centeio \\ Wayne State University University of Hawaii at Manoa \\ Paige Arvidson and Kowsar Hijazi \\ Wayne State University
}

\begin{abstract}
Purpose: This exploratory study evaluated how youth healthy eating (HE) and physical activity (PA) behaviors could be influenced by a whole-of-school program, which was transformed to a virtual setting at the onset of the COVID-19 pandemic. The authors investigated how students experienced programming and the role of students' perceptions of parental support in their self-reported engagement in HE and PA. Methods: PA and HE curricula were provided across 15 schools over 12 weeks. Students $\left(N=879, M_{\text {age }}=12.12\right.$ years, 63\% female) completed a survey evaluating the value and perceptions around programmatic aspects as well as their self-reported engagement in HE and PA. Results: Multiple regression analyses revealed positive relationships between parental support for PA and student engagement, as well as positive relationships between students' self-efficacy and HE behaviors. Conclusion: Findings indicate that students utilized virtual HE and PA programming and that parent support helped to facilitate engagement in PA and HE behaviors beyond the school setting.
\end{abstract}

Keywords: parental engagement, stay-at-home orders, virtual health programming

The COVID-19 pandemic has resulted in widespread, multifaceted hardships ranging from overwhelmed hospital systems to shelter-in-place orders. In March 2020, stay-at-home (lockdown) orders were executed nationwide, calling for people to shelter in their homes, with the exception of leaving for essential reasons like grocery shopping. In conjunction with the widespread stay-athome orders, most schools closed. An estimated $87 \%$ of youth worldwide were impacted by school closures, which forced student learning unexpectedly into virtual classroom settings (United Nations Educational, Scientific and Cultural Organization, 2020). The pivot to remote learning was intended to last only a few weeks, but the worsening pandemic prevented many schools from reopening their campuses for the remainder of the year. An unintentional but significant repercussion of the shift was an increase in youths' screen time and sedentary minutes (United Nations Educational, Scientific and Cultural Organization, 2020). Perhaps more problematic is the ever-changing threat of infection associated with the COVID-19 pandemic (i.e., new variants) despite vaccination rollouts. This continued fear and uncertainty of contracting COVID-19 may continue to contribute to physical inactivity and sedentary behaviors as we continue to live in and navigate a virtual or physically distanced world (Hall, Laddu, Phillips, Lavie, \& Arena, 2020).

The focus of the present study was on the viability of transitioning a brick and mortar whole-of-school health program to

Barcelona, Arvidson, and Hijazi are with the Department of Kinesiology, Health and Sports Studies, Wayne State University, Detroit, MI, USA. Centeio is with the Department of Kinesiology and Rehabilitation Science, University of Hawaii at Manoa, Honolulu, HI, USA. Barcelona (Jeanne.barcelona@wayne.edu) is corresponding author. virtual delivery during the initial wave of the pandemic (MarchJune, 2020). The Dearborn School Health through Integrated Nutrition and Exercise Strategies (D-SHINES) program went virtual in March 2020, in order to support student and family healthy eating (HE) and physical activity (PA) in the home environment. The D-SHINES program is grounded in the Whole School, Whole Community, Whole Child (WSCC) framework, including a Comprehensive School Physical Activity Program (CSPAP; Kelder, Karp, Scruggs, \& Brown, 2014). The WSCC framework urges educators to adopt a comprehensive approach, thinking in terms of whole child development, which emphasizes that youths need to be surrounded by ample resources and support within their school settings, in their homes, and by their surrounding communities, to foster academic, physical, and mental growth (Association for Supervision and Curriculum Development, 2014). The CSPAP model also asserts a comprehensive approach to facilitating whole child development that prioritizes students' access to PA across the school day (Carson \& Webster, 2019). Both models further assert the importance of reinforcing healthy behaviors adopted in the school setting through family and community engagement (FCE), yet there is a lack of literature providing evidence of the efficacious of this component within the larger framework (Cipriani, Richardson, \& Roberts, 2012).

To date, the majority of research available focuses on components of WSCC and CSPAP housed in the school setting, indicating that school-based programming yields comprehensively efficacious outcomes in youth, including increased PA and HE, reduced obesity status, and increased academic achievement and attendance (Brusseau, Hannon, \& Burns, 2016; Centeio et al., 2014, 2021). Furthermore, the WSCC and CSPAP frameworks were conceptualized in traditional school settings, posing challenges 
to translate them into the newly adopted virtual school setting. For example, children traditionally spend $8 \mathrm{hr}$ at school-one of the primary justifications within the WSCC and CSPAP model for prioritizing schools as the ideal setting to improve children's health outcomes (Center for Disease Control and Prevention, 2019). However, at the onset of the pandemic, youth were no longer able to spend their waking hours in schools, and their physical education (PE) was stagnated and PA declined (Pavlovic et al., 2021). Despite national calls to offer virtual PA opportunities for youth, schools and teachers were overwhelmed and could not support student needs beyond core content (Iqbal \& Tayyab, 2021). Schools soon realized that to support student health needs, such as PA and HE, they would need to shift their primary focus from providing healthy opportunities in the traditional school setting to conceptualizing how they could maximize family and parental engagement knowing that FCE, to date, has been an underutilized component of a comprehensive school health approach (Perez, Thalken, Ughelu, Knight, \& Massey, 2020). This was difficult given the lack of research evidence to inform practices to support youth PA and HE virtually and through FCE.

As such, the aim of this exploratory study was to understand how $\mathrm{HE}$ and PA behaviors of youth could be influenced by a wholeof-school program that was transformed to a virtual setting at the onset of the COVID-19 pandemic. Specifically, we investigated how students experienced programming, exploring the relationship between students' perceptions of parental support, enjoyment, and value in virtual programming as well as their self-efficacy toward $\mathrm{HE}$ and their self-reported health behaviors. Also, given the unique lockdown time period, this study also sought to understand the relationship of students' perceptions of parental support during the pandemic and youth PA behavior during that time.

\section{Method}

During the 2018-2020 school years, 15 schools in a Midwestern school district participated in D-SHINES, a whole-of-school approach program. D-SHINES aims to nurture a healthy school environment where teachers, students, and families are afforded the resources necessary to implement a healthy living ideology. The DSHINES program has five components developed to facilitate behavior change: (a) PE, (b) classroom PA breaks, (c) before and after-school PA programs, (d) garden education, and (e) FCE. Traditional in-school programming was halted in March 2020 when stay-at-home orders were issued due to the increasing COVID-19 cases, but, within a week of the closures, the intervention team began developing and disseminating virtual content to students and their families.

The D-SHINES program tailored content and resources specific to PA and nutrition, making them virtually accessible. Daily PA and nutrition lessons were provided over 12 weeks from March to June, 2020. The content was culturally relevant and tailored to a low-income, predominantly Arab American community, reaching elementary and middle school students (aged 4-13 years) and their parents. For the purpose of this study, the content was distributed via e-mail to the PE and classroom teachers, as well as to the principals, for them to pass along to students and parents as part of their "at-home" learning materials. The PE and PA lesson topics were in alignment with National and State PE Standards (Michigan Department of Education, 2017; SHAPE, 2020) and included health-related fitness, yoga, mindfulness, high-intensity interval training, and skills-based activities. In addition, daily nutrition topics, aligned with U.S. Department of Agriculture (USDA) guidelines were provided (USDA, 2015). For more information on D-SHINES, visit: https://www.healthykidsshine.org/. Given the large proportion of Arab American families in the district, the content was translated to Arabic to ensure content was accessible to parents and students. Furthermore, since the stay-at-home orders ran through Ramadan, a month-long time of fasting and spiritual reflection observed by Arab American families, D-SHINES developed culturally relevant PA and nutrition content that was sensitive to and could be integrated into daily fasting.

\section{Participants and Data Collection}

Following the 12 weeks of lessons provided to 15 elementary and middle school sites reaching 10,296 students, physical educators across 12 of the sites agreed to send upper elementary and middle school students a link to an electronic survey. Three of the school sites chose not to have their students participate in the completion of the electronic survey due to their concerns about student workload during COVID-19. Physical educators sent the link to 2,543 students explaining that it was not mandatory, and 35\% $\left(N=879, M_{\text {age }}=12.2\right.$ years, age range $=9-13$ years, $63 \%$ female $)$ completed the electronic survey. Among participants, the largest proportion, $75 \%$ of students, indicated they were of Arab American or Middle Eastern descent, followed by White (13\%) and Black (3\%). The survey assessed students' PA lesson interest, enjoyment, and engagement, and perceptions of parental support and engagement, nutritional habits, and student efficacy toward HE during the stay-at-home order. In addition, the survey included demographic items (i.e., age, sex, grade level, and ethnicity).

\section{Data Sources}

The PA was measured using two questions that elicited a 7-day recall. The PA questions included in the survey are validated and used as surveillance questions with the Youth Risk Behavior Surveillance System (United States Department of Health and Human Services, 2019). One example is "During the past 7 days, on how many days were you physically active for a total of at least 60 minutes per day?" The fruit and vegetable (F\&V) consumption questions were pulled from a modified version of the Survey of PA and Nutrition (Thiagarajah et al., 2008). The questions used were the questions pertaining specifically to $\mathrm{F} \& \mathrm{~V}$ consumption from that specific tool. An example is "During the past 7 days, how many times did you eat fruit?" Student perceptions of parental support for PA was measured using the five-item parental social support scale (Duncan, Duncan, \& Strycker, 2005). The scale for these questions was a 5-point Likert scale that ranged from 1 (never) to 5 (very often). An example from this scale is, "How much does your parents or the adult that takes care of you, encourage you to do PA?" There was one question omitted from the social support scale as it was specific to parents taking kids to PA events. Given the COVID-19 situation, it was decided that it was inappropriate to include this in the scale. Efficacy toward HE questions was used but was modified for the specific intervention as intended in the scale development (Schwarzer et al., 2007). There were a total of two questions: one specific to fruit and one to vegetables. These questions had a 4-point Likert scale that ranged from 5 (I really like) to 1 (I really don't like). An example includes "How do you feel about eating vegetables?" Finally, there was a series of questions that were specific to the online experience itself and valuing the D-SHINES program and activities. Questions were adapted from the expectancy value questionnaire (Xiang, McBride, 
Guan, \& Solmon, 2003) and had been adapted previously for a similar program in a face-to-face environment (Garn, Centeio, Shen, Martin, \& McCaughtry, 2016). An example of a question is "The PA lessons provided to me during the school closure were a valuable part of my life." The responses were given on a 1-5 Likert scale.

\section{Data Analysis}

Data were screened for missingness and outliers before analyses. Descriptive statistics explored student demographics, including sex, age, and ethnicity. Percentages of generalized engagement in PA and HE were also calculated. Two-tailed bivariate correlations were utilized to identify significant associations among variables of interest, including student-reported PA and HE behaviors, student value of lessons, perceptions of parental engagement, and efficacy toward HE. A series of multiple regression analyses were employed to determine the predictive power of significant correlational associations. Individual and multivariate assumptions were met in conjunction with each analysis, indicating that variables exhibited linearity and normality with no detection of multicollinearity $(\mathrm{VIF}<10)$. Statistical significance was set at $p<.05$. Data analyses were performed using SPSS (version 25.0; IBM Corp., Armonk, NY).

\section{Results}

For self-reported PA behaviors, 50\% of students stated they engaged in 60 min of PA at least 5 days a week, and $62 \%$ reported engaged in at least 3 days of strength-related PA within the past 7 days. For F\&V consumption, $74 \%$ of students reported eating green vegetables, and $84 \%$ reported eating fruit as part of a 1-day recall.

Bivariate correlations examined the associations among student health behaviors, the extent to which they valued the virtual programming, and their perceptions around parental support and engagement in PA. As highlighted in Table 1, results indicated significant associations between youths' self-reported engagement in PA, the value they placed on the virtual PA lessons provided, and their perceptions of their parents' encouragement of PA. Grade was associated with value of PA levels; sex had associations with PA behavior and efficacy toward F\&V intake. Ethnicity was associated with strength-based PA behavior and F\&V consumption. Students' self-reported engagement in PA and strength-based PA was also significantly correlated with their value of the virtual PA lessons and parental encouragement. Finally, students' self-reported F\&V consumption was significantly associated with student efficacy toward HE.

Table 1 Correlations Between PA, HE, and Psychosocial Factors

\begin{tabular}{|c|c|c|c|c|c|c|c|c|c|c|c|c|c|c|c|c|c|c|c|}
\hline & 2 & 3 & 4 & 5 & 6 & 7 & 8 & 9 & 10 & 11 & 12 & 13 & 14 & 15 & 16 & 17 & $M$ & $S D$ & Range \\
\hline 1. Grade & .03 & -.19 & .03 & .04 & .04 & -.04 & -.20 & -.10 & -.09 & -.09 & -.05 & -.04 & -.10 & -.01 & .04 & -.01 & 6.58 & 1.24 & $3-8$ \\
\hline 2. Sex & & -.09 & -.05 & -.09 & -.01 & .02 & -.01 & -.01 & -.01 & .02 & -.07 & -.03 & -.04 & -.05 & .13 & .11 & 1.63 & 0.48 & $0-1$ \\
\hline 3. Ethnicity & & & -.05 & -.11 & -.14 & -.09 & -.01 & -.03 & -.03 & -.01 & .01 & -.03 & .05 & -.03 . & .01 & -.01 & 0.24 & 0.42 & $0-1$ \\
\hline $\begin{array}{l}\text { 4. } 60 \text { min of MVPA } \\
\text { for past } 7 \text { days }\end{array}$ & & & & .45 & .15 & .19 & .17 & .22 & .13 & .17 & .24 & .16 & .22 & .14 & .11 & .10 & 4.45 & 1.97 & $0-7$ \\
\hline $\begin{array}{l}\text { 5. Strength-based PA } \\
\text { in past } 7 \text { days }\end{array}$ & & & & & .19 & .15 & .14 & .22 & .11 & .20 & .17 & .22 & .20 & .16 & .04 & .11 & 3.49 & 2.37 & $0-7$ \\
\hline $\begin{array}{l}\text { 6. Green vegetable } \\
\text { consumption }\end{array}$ & & & & & & .30 & .06 & .13 & .04 & .08 & .11 & .15 & .16 & .14 & .03 & .17 & 1.16 & 1.06 & $0-5$ \\
\hline 7. Fruit consumption & & & & & & & .03 & .04 & .01 & .07 & .17 & .07 & .06 & .07 & .20 & .08 & 1.94 & 1.44 & $0-5$ \\
\hline $\begin{array}{l}\text { 8. PA lessons were } \\
\text { fun }\end{array}$ & & & & & & & & .61 & .42 & .48 & .17 & .14 & .1 & .12 & .14 & .13 & 3.86 & 1.01 & $1-5$ \\
\hline $\begin{array}{l}\text { 9. PA lessons were } \\
\text { valuable }\end{array}$ & & & & & & & & & .38 & .58 & .19 & .23 & .24 & .20 & .11 & .11 & 3.76 & 1.05 & $1-5$ \\
\hline $\begin{array}{l}\text { 10. PA lessons were } \\
\text { exciting }\end{array}$ & & & & & & & & & & .34 & .04 & .12 & .08 & .08 & .05 & .10 & 3.67 & 1.08 & $1-5$ \\
\hline $\begin{array}{l}\text { 11. PA lessons } \\
\text { improved my health }\end{array}$ & & & & & & & & & & & .17 & .18 & .19 & .12 & .08 & .10 & 3.95 & 1.05 & $1-5$ \\
\hline $\begin{array}{l}\text { 12. Parent en- } \\
\text { courages PA }\end{array}$ & & & & & & & & & & & & .46 & .42 & .50 & .09 & .07 & 4.25 & 0.97 & $1-5$ \\
\hline $\begin{array}{l}\text { 13. Parent does PA } \\
\text { with you }\end{array}$ & & & & & & & & & & & & & .51 & .50 & .07 & .10 & 3.42 & 1.25 & $1-5$ \\
\hline $\begin{array}{l}\text { 14. Parent watches } \\
\text { your PA }\end{array}$ & & & & & & & & & & & & & & .49 & .01 & .08 & 3.61 & 1.25 & $1-5$ \\
\hline $\begin{array}{l}\text { 15. Parent talks with } \\
\text { you about PA }\end{array}$ & & & & & & & & & & & & & & & .03 & .04 & 3.47 & 1.276 & $1-5$ \\
\hline $\begin{array}{l}\text { 16. Feelings about } \\
\text { eating fruit }\end{array}$ & & & & & & & & & & & & & & & & .40 & 4.59 & 0.740 & $1-5$ \\
\hline $\begin{array}{l}\text { 17. Feelings about } \\
\text { eating vegetables }\end{array}$ & & & & & & & & & & & & & & & & - & 3.80 & 1.092 & $1-5$ \\
\hline
\end{tabular}

Note. Bold values are significant. Reference for grade is third, reference for sex is male, and reference for ethnicity is Arab American. PA= physical activity; HE = healthy eating; MVPA = moderate- to vigorous-intensity PA. 
A series of hierarchical multiple regression analyses examined the predictive power of students' value of virtual lessons as well as their perceptions of parent/guardian encouragement on levels of self-reported PA engagement. Detailed regression analyses data can be found in Table 2. The first multiple regression analysis examined students' engagement in $60 \mathrm{~min}$ of daily PA as the outcome variable, with grade, sex, and ethnicity as predictors in Step 1 and variables of parental encouragement of PA in Step 2. Step 1 was not significant, while Step 2 of the model reached significance, adjusted (adj) $R^{2}=.08, F(7,851)=10.89, p<.001$, suggesting that parents watching and encouraging PA with their children was predictive of their PA. In the second analysis, students' strength-based PA was used as the outcome variable, with grade, sex, and ethnicity as predictors in Step 1 and variables of parent encouragement of PA in Step 2. Step 1 revealed significance with sex and ethnicity being significant contributors, adj $R^{2}=.02, F(3,856)=6.92, p<.001$. Significance was reached in Step 2, suggesting that parents watching, talking about, and engaging in strength-based PA with their child were significant predictors of their strength-based PA, adj $R^{2}=.09, \quad F(7$, $852)=11.95, p<.001$. Sex and ethnicity were also significant in Step 2, revealing that Arab American males were most likely to engage in strength-based PA.

The next series of hierarchical multiple regressions analyzed students' perceptions of the virtual PA lessons given by D-SHINES with student engagement in PA. The first analysis used student selfreported PA as the outcome variable and with grade, sex, and ethnicity as predictors in Step 1 and students' perceptions of the virtual PA lessons in Step 2. Step 1 was not significant, but Step 2 was significant, adj $R^{2}=.05, F(7,851)=12.63, p<.001$, indicating students' value of the virtual PA lessons was a significant predictor of PA while controlling for grade, sex, and ethnicity. Similarly, the second regression in this series used student engagement in strength-based PA as the outcome variable, with grade, sex, and ethnicity as predictors in Step 1, and students' perceptions of the virtual PA lessons in Step 2. This time, Step 1, adj $R^{2}=.02$, $F(3,855)=7.18, \quad p<.001$, and Step 2, adj $R^{2}=.07, F(7$, $851)=13.01, p<.001$, were both significant. In the final model, both sex and ethnicity were significant in addition to students' value of the lesson and believing that the virtual lessons improved their health. Analysis of variance as a post hoc analysis revealed that Arab American males $(p<.01)$ were the most likely to engage.

The final series of hierarchical multiple regression analyses examined the relationship between students' efficacy toward $\mathrm{HE}$ and their self-reported F\&V consumption. In the first analysis, predictors of green vegetable consumption were analyzed. In the first step, which included variables of grade, sex, and ethnicity, ethnicity was a significant predictor of vegetable consumption, adj $R^{2}=.02, F(3,829)=5.48, p<.001$. In the second step of the model, student ethnicity and student efficacy toward eating vegetables were significant predictors of vegetable consumption, adj $R^{2}=.04, F(7,825)=6.28, p<.001$. In a similar analysis, we investigated how student efficacy toward eating $\mathrm{F} \& \mathrm{~V}$, healthy snacks, and drinking water may predict fruit consumption. In the first step, which included variables of grade, sex and ethnicity, ethnicity was a significant predictor of fruit consumption, adj $R^{2}=.01, F(3,830)=3.29, p=.02$. The second step revealed ethnicity and student efficacy toward eating fruit, and attitude toward healthy snacks was a significant predictor of fruit consumption, adj $R^{2}=.06, F(7,826)=11.60$, $p<.001$.

\section{Discussion}

The results of this study suggest that programmatic activities representative of comprehensive school-based health programming can be translated into valuable virtual learning opportunities for youth and families. Specifically, youth self-reported data indicated that the PA content provided during the COVID-19 pandemic was valuable and even predicted youths' ability to meet PA guidelines throughout the stay-at-home orders. This is promising given that our understanding of the overall effects of the COVID-19 stay-athome orders on children's long-term health outcomes are everevolving. Recent studies on the impact of the stay-at-home and physical distancing orders due to the pandemic indicate that youth have significantly decreased their PA minutes and increased their screen time (Bates et al., 2020; Dunton, Do, \& Wang, 2020; Munasinghe et al., 2020). Munasinghe et al. (2020) further reported that the pandemic has created new barriers for youth PA, such as a lack of access to green spaces, sports cancellations, and face-toface schooling being delayed. The findings of this study suggest that youth valued virtual at-home PA programming and, in doing so, perhaps buffered a decline in PA during the pandemic. Youths' value of and engagement in the virtual programming show promise in its potential to serve as a mechanism, into the future and beyond the pandemic, to encourage youth to be physically active above and beyond opportunities offered in the school setting. Future research should explore the use of virtual programming within whole-ofschool approaches specifically looking to understand how youth perceive and value it and how these factors impact youth PA engagement.

The current study also sheds light on parental engagement in relation to youth PA. Our results suggest that parents watching, talking about, and engaging in PA were significant predictors of youths' self-reported PA and strength-based PA. This is important because comprehensive, whole-of-school-based programs have historically identified the school setting as the most opportune environment to increase youth PA, while finding parents and the home setting more challenging to engage with (Cipriani et al., 2012). Research related to WSCC and CSPAP implementation has exhibited a greater focus on investigating teacher-, student-, and school-level factors related to PA outcomes (Erwin, Beighle, Carson, \& Castelli, 2013; Hunt \& Metzler, 2017). However, research independent of comprehensive approaches has suggested that parental engagement is significantly associated with youth PA engagement (Edwardson \& Gorely, 2010; Gilic, Ostojic, Corluka, Volaric, \& Sekulic, 2020). Given that the findings of this study also support the value of parental engagement within the context of comprehensive school approaches, future development of comprehensive, whole-of-school-based interventions may look at the significance of prioritizing both school and FCE components. We recognize that the initial stay-at-home orders that accompanied the COVID-19 outbreak in spring of 2020 have been explained as being part of an unusual time in history that cannot be replicated where families sheltered in place together for an extended period of time, yet we must assert that future intervention work should be informed by what we learned from this historical event. If there is any lesson that schools and communities can learn from the crippling effects of COVID-19 it is that programming, resources, and activities must be nimble. We can no longer prioritize one setting over another, rather the progression of whole-of-school approaches most look to purposefully provide virtual and in-person PA opportunities for youth to participate in across the school, home, and community settings. 


\begin{tabular}{|c|c|c|c|c|c|c|c|c|}
\hline & \multirow[b]{2}{*}{ B } & \multirow[b]{2}{*}{ SE } & \multirow[b]{2}{*}{$\boldsymbol{\beta}$} & \multirow[b]{2}{*}{$t$} & \multirow[b]{2}{*}{$p$} & \multicolumn{2}{|c|}{$95 \% \mathrm{Cl}$} & \multirow[b]{2}{*}{ VIF } \\
\hline & & & & & & LL & UL & \\
\hline \multicolumn{9}{|l|}{ Regression 1 (60 min PA) } \\
\hline \multicolumn{9}{|c|}{ Model 1: $\operatorname{adj} R^{2}=.01, F(3,855)=1.51, p=.21$} \\
\hline Grade & 0.02 & 0.05 & 0.01 & .39 & .70 & -0.08 & 0.13 & 1.04 \\
\hline Sex & -0.21 & 0.14 & -0.05 & -1.48 & .14 & -0.48 & 0.07 & 1.00 \\
\hline Ethnicity & -0.24 & 0.16 & -0.05 & -1.48 & .14 & -0.55 & 0.08 & 1.04 \\
\hline \multicolumn{9}{|c|}{ Model 2: $\operatorname{adj} R^{2}=.08, F(7,851)=10.89, p<.001$} \\
\hline Grade & 0.07 & 0.05 & 0.04 & 1.23 & .22 & -0.04 & 0.17 & 1.05 \\
\hline Sex & -0.16 & 0.13 & -0.04 & -1.15 & .25 & -0.42 & 0.11 & 1.01 \\
\hline Ethnicity & -0.26 & 0.15 & -0.06 & -1.66 & .10 & -0.56 & 0.05 & 1.05 \\
\hline Parent encourages PA & 0.37 & 0.08 & 0.18 & 4.54 & .00 & 0.21 & 0.52 & 1.49 \\
\hline Parent does PA & 0.04 & 0.06 & 0.02 & .541 & .59 & -0.09 & 0.16 & 1.59 \\
\hline Parent watches PA & 0.26 & 0.06 & 0.16 & 4.01 & .00 & 0.13 & 0.38 & 1.55 \\
\hline Parent talks about PA with you & -0.07 & 0.06 & -0.04 & -1.12 & .26 & -0.20 & 0.05 & 1.62 \\
\hline \multicolumn{9}{|l|}{ Regression 2 (strengthening PA) } \\
\hline \multicolumn{9}{|c|}{ Model 1: adj $R^{2}=.02, F(3,856)=6.92, p<.001$} \\
\hline Grade & 0.05 & 0.07 & 0.03 & .73 & .46 & -0.08 & 0.18 & 1.04 \\
\hline Sex & -0.50 & 0.17 & -0.10 & -2.97 & .01 & -0.82 & -0.17 & 1.01 \\
\hline Ethnicity & -0.65 & 0.19 & -0.12 & $-\mathbf{3 . 3 9}$ & .01 & -1.02 & -0.27 & 1.05 \\
\hline \multicolumn{9}{|c|}{ Model 2: adj $R^{2}=.09, F(7,852)=11.95, p<.001$} \\
\hline Grade & 0.09 & 0.10 & 0.08 & 1.91 & .06 & -0.03 & 0.22 & 1.05 \\
\hline Sex & -0.45 & 0.08 & 0.13 & 3.30 & .01 & -0.77 & -0.13 & 1.01 \\
\hline Ethnicity & -0.63 & 0.08 & 0.11 & 2.80 & .01 & -0.99 & -0.27 & 1.05 \\
\hline Parent encourages PA & 0.18 & 0.07 & -0.01 & -.27 & .78 & -0.01 & 0.37 & 1.49 \\
\hline Parent does PA & 0.26 & $\mathbf{0 . 1 0}$ & 0.08 & 1.91 & .05 & 0.10 & 0.41 & 1.59 \\
\hline Parent watches PA & 0.22 & 0.08 & 0.14 & 3.30 & .01 & 0.06 & 0.37 & 1.55 \\
\hline Parent talks about PA with you & -0.02 & $\mathbf{0 . 0 8}$ & 0.11 & 2.80 & .01 & -0.17 & 0.13 & 1.63 \\
\hline \multicolumn{9}{|l|}{ Regression 3 (60 min PA) } \\
\hline \multicolumn{9}{|c|}{ Model 1: $\operatorname{adj} R^{2}=.01, F(3,855)=1.69, p=.17$} \\
\hline Grade & 0.02 & 0.05 & 0.02 & .68 & .50 & -0.09 & 0.13 & 1.04 \\
\hline Sex & -0.22 & 0.14 & -0.05 & -1.44 & .15 & -0.50 & 0.06 & 1.01 \\
\hline Ethnicity & -0.26 & 0.04 & -0.01 & -.14 & .89 & -0.57 & 0.06 & 1.04 \\
\hline \multicolumn{9}{|c|}{ Model 2: $\operatorname{adj} R^{2}=.05, F(7,851)=12.63, p<.001$} \\
\hline Grade & 0.06 & 0.05 & 0.05 & 1.57 & .12 & -0.04 & 0.17 & 1.08 \\
\hline Sex & -0.21 & 0.14 & 0.05 & -1.40 & .16 & -0.48 & 0.06 & 1.01 \\
\hline Ethnicity & -0.20 & 0.04 & -0.02 & -.63 & .53 & -0.51 & 0.11 & 1.05 \\
\hline Lessons were fun & 0.13 & 0.09 & 0.05 & 1.20 & .23 & -0.05 & 0.31 & 1.92 \\
\hline Lessons valuable & 0.29 & 0.09 & 0.15 & 3.31 & .00 & 0.11 & 0.46 & 2.05 \\
\hline Lessons were exciting & -0.01 & 0.04 & 0.04 & .98 & .33 & -0.18 & 0.16 & 2.02 \\
\hline Lessons improved my health & 0.11 & 0.08 & 0.05 & 1.27 & .20 & -0.04 & 0.26 & 1.63 \\
\hline \multicolumn{9}{|l|}{ Regression 4 (strengthening PA) } \\
\hline \multicolumn{9}{|c|}{ Model 1: $\operatorname{adj} R^{2}=.02, F(3,855)=7.18, p<.001$} \\
\hline Grade & 0.06 & 0.07 & 0.030 & .868 & .38 & -0.072 & 0.186 & 1.038 \\
\hline Sex & -0.48 & 0.17 & -0.10 & -2.87 & .01 & -0.810 & -0.152 & 1.007 \\
\hline Ethnicity & -0.68 & 0.19 & -0.12 & -3.53 & .01 & -1.055 & -0.302 & 1.044 \\
\hline \multicolumn{9}{|c|}{ Model 2: adj $R^{2}=.07, F(7,851)=13.01, p<.001$} \\
\hline Grade & 0.12 & 0.06 & 0.06 & 1.76 & .08 & -0.01 & 0.24 & 1.07 \\
\hline Sex & -0.47 & 0.16 & -0.09 & -2.90 & .01 & -0.79 & -0.15 & 1.01 \\
\hline Ethnicity & -0.61 & 0.19 & -0.11 & -3.25 & .01 & -0.98 & -0.24 & 1.05 \\
\hline Lessons were fun & 0.01 & 0.11 & 0.01 & .05 & .95 & -0.21 & 0.22 & 1.92 \\
\hline
\end{tabular}




\begin{tabular}{|c|c|c|c|c|c|c|c|c|}
\hline & \multirow[b]{2}{*}{$B$} & \multirow[b]{2}{*}{ SE } & \multirow[b]{2}{*}{$\boldsymbol{\beta}$} & \multirow[b]{2}{*}{$t$} & \multirow[b]{2}{*}{$p$} & \multicolumn{2}{|c|}{$95 \% \mathrm{Cl}$} & \multirow[b]{2}{*}{ VIF } \\
\hline & & & & & & LL & UL & \\
\hline Lessons valuable & 0.31 & 0.11 & 0.14 & 2.89 & .01 & 0.10 & 0.51 & 2.05 \\
\hline Lessons were exciting & 0.08 & 0.10 & 0.04 & .81 & .41 & -0.12 & 0.28 & 2.02 \\
\hline Lessons improved my health & 0.23 & 0.09 & 0.10 & 2.39 & .01 & 0.04 & 0.41 & 1.62 \\
\hline \multicolumn{9}{|l|}{ Regression 5 (green vegetables) } \\
\hline \multicolumn{9}{|c|}{ Model 1: adj $R^{2}=.02, F(3,829)=5.48, p<.001$} \\
\hline Grade & 0.01 & 0.03 & 0.02 & .53 & .59 & -0.04 & 0.07 & 1.04 \\
\hline Sex & -0.03 & 0.07 & -0.01 & -.38 & .69 & -0.18 & 0.12 & 1.00 \\
\hline Ethnicity & -0.34 & 0.09 & -0.14 & -3.84 & .00 & -0.51 & -0.16 & 1.04 \\
\hline \multicolumn{9}{|c|}{ Model 2: $\operatorname{adj} R^{2}=.04, F(7,825)=6.28, p<.001$} \\
\hline Grade & 0.02 & 0.03 & 0.02 & .67 & .50 & -0.03 & 0.07 & 1.04 \\
\hline Sex & -0.06 & 0.08 & -0.03 & -.85 & .39 & -0.21 & 0.08 & 1.02 \\
\hline Ethnicity & -0.34 & 0.09 & -0.14 & -3.93 & .00 & -0.51 & -0.17 & 1.05 \\
\hline Feelings about eating fruit & -0.03 & 0.06 & -0.02 & -.53 & .60 & -0.14 & 0.08 & 1.36 \\
\hline Feelings about eating vegetables & 0.16 & 0.04 & 0.17 & 4.35 & .00 & 0.09 & 0.23 & 1.26 \\
\hline Feelings about drinking water & -0.02 & 0.04 & -0.02 & -.52 & .60 & -0.10 & 0.05 & 1.16 \\
\hline Feelings about eating healthy snacks & 0.06 & 0.04 & 0.05 & 1.53 & .13 & -0.10 & 0.15 & 1.29 \\
\hline \multicolumn{9}{|l|}{ Regression 6 (fruit) } \\
\hline \multicolumn{9}{|c|}{ Model 1: $\operatorname{adj} R^{2}=.01, F(3,830)=3.29, p=.02$} \\
\hline Grade & -0.06 & 0.04 & -0.05 & -1.55 & .12 & -0.14 & 0.02 & 1.04 \\
\hline Sex & 0.02 & 0.10 & 0.01 & .24 & .81 & -0.18 & 0.23 & 1.01 \\
\hline Ethnicity & -0.35 & 0.12 & -0.10 & -2.94 & .01 & -0.58 & -0.12 & 1.05 \\
\hline \multicolumn{9}{|c|}{ Model 2: adj $R^{2}=.06, F(7,826)=11.60, p<.001$} \\
\hline Grade & -0.07 & 0.04 & -0.06 & -1.65 & .10 & -0.14 & 0.01 & 1.05 \\
\hline Sex & -0.05 & 0.10 & -0.02 & -.46 & .65 & -0.25 & 0.15 & 1.03 \\
\hline Ethnicity & -0.35 & 0.12 & -0.10 & -3.02 & .01 & -0.58 & -0.12 & 1.06 \\
\hline Feelings about eating fruit & 0.36 & $\mathbf{0 . 0 8}$ & 0.18 & 4.60 & .01 & 0.21 & 0.52 & 1.36 \\
\hline Feelings about eating vegetables & -0.03 & 0.05 & -0.02 & -.59 & .56 & -0.13 & 0.07 & 1.25 \\
\hline Feelings about drinking water & 0.05 & 0.05 & 0.03 & .87 & .39 & -0.06 & 0.15 & 1.16 \\
\hline Feelings about eating healthy snacks & 0.13 & 0.06 & 0.09 & 2.22 & .03 & 0.02 & 0.25 & 1.30 \\
\hline
\end{tabular}

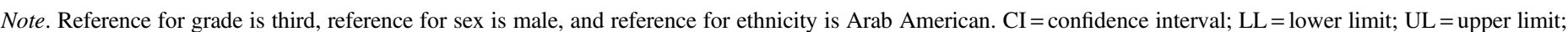
$\mathrm{VIF}=$ variance inflation factor; $\mathrm{PA}=$ physical activity. Bold values indicate significant results with $p$ value $<.05$.

Finally, results from the current study suggested that youth selfefficacy toward HE behaviors predicted their self-reported F\&V consumption. Initially, this may not appear to be a novel finding. Yet, research suggests that belief in one's ability to access healthy foods and engage in HE habits may not result in improved behaviors (Ortega et al., 2016). Furthermore, research captured among Australian youth during the COVID-19 pandemic suggests that even with a lack of access to fast foods and increased access to $\mathrm{F} \& \mathrm{~V}$, youth $\mathrm{F} \& \mathrm{~V}$ consumption did not change, suggesting that simply providing access to $\mathrm{F} \& \mathrm{~V}$ may not be enough to motivate youth consumption (Munasinghe et al., 2020). Under this premise, the current study findings may suggest that the combination of virtual HE activities provided through D-SHINES and access to F\&V in the home setting may have fostered optimal conditions for youth to feel efficacious toward HE, which resulted in their self-reported consumption. Future studies may seek to further investigate aspects of virtual HE programming as well as factors within the home setting that influence youth self-efficacy and consumption of F\&V.

Taken collectively, the results of the current study demonstrate the value and importance of translating traditional whole-ofschool health programming online. Before the pandemic began,
D-SHINES was proficient programming in the school setting that provided newsletters to families. One week into the March 2020 stay-at-home orders and school closures, D-SHINES shifted most of their PA and HE content online in a meaningful way. Our goal was to provide schools with quality content that could be shared with parents to implement in the home setting. This was by far more successful than we could ever have imagined, with results indicating that students valued the content provided and that it supported healthy behaviors during the pandemic. When access to the outside world was limited, the D-SHINES program developed virtual activities for students and families so that they could be active and eat healthily together.

The current study concluded in June 2020, yet the COVID-19 pandemic has continued. As such, the next big steps for future whole-of-school interventions will be identifying ways to keep the momentum going; virtually engaging with youth, families, and schools through the ongoing pandemic; and looking ahead to what engagement looks like in nonpandemic times. We cannot lose sight of the lessons we are learning through the COVID-19 pandemicone being that we were able to engage students and families in virtual at-home PA and $\mathrm{HE}$ programming. Yet, given the 
unprecedented circumstances that everyone was facing, we have to wonder if utilizing virtual engagement is a sustainable strategy. Future research should explore the sustainability of virtual programming and how it relates to student and family engagement in whole-of-school approaches going forward.

\section{Limitations}

Although there are many strengths to this study, including the number of students who participated during the pandemic, there are also many limitations. First, there is no control group present in this study. Given the situation with COVID-19, coupled with the comprehensive district approach, we were unable to compare the results with students who did not participate in D-SHINES programming. Second, given the time the survey was taken, and the taxing nature of the ongoing pandemic at the time (end of the school year while in shutdown), researchers did not want to burden the participating students. Therefore, the survey was kept purposefully short and was less detailed, using validated questions to measure behaviors instead of full scales. Further, given the time constraints that the researchers were under, there was no time to confirm validity and reliability of the modified survey prior to use. This limits the conclusions that can be drawn from the research conducted. To that point, the use of a survey itself for data collection is another limitation of this study, as surveys have a high instance of bias. Direct and objective measures, especially in lieu of the self-reported PA recall, to accurately capture PA engagement would be ideal. However, given the immediate nature of the study, and the stay-at-home orders in place, the use of surveys was necessary and acceptable (Sirard, Hannan, Cutler, \& Nuemark-Sztainer, 2013).

A final limitation of the study is that the sample participants were primarily Arab American. While this provides a unique insight into a virtual PA interventions' impact within this specific ethnic group, it is not necessarily generalizable to the greater population. Future studies on this topic should expand the sample to include a wider range of ethnicities within the participant pool.

Despite these limitations, we feel that these data are very unique and important to the research base. Given that we were already established in the school setting, coupled with the district and researchers' willingness to pivot quickly, we were able to capture a glimpse of students' experiences in D-SHINES during the COVID-19 pandemic. There were few studies at the time of this study that captured student-level PA and HE data during COVID-19. Given this uniqueness, we feel the data are valuable to inform what went on during the spring 2020 shutdown and hopefully inform future programming both for the remainder and beyond the pandemic.

\section{Acknowledgments}

The authors thank the Michigan Health Endowment Fund for its support of the Dearborn SHINES program, especially during the COVID-19 pandemic. This work was supported by a grant from the Michigan Health Endowment Fund (no.: R-1902-144093).

\section{References}

Association for Supervision and Curriculum Development. (2014). Whole school, whole community, whole child. Retrieved from http://www. ascd.org/programs/learning-and-health/wscc-model.aspx
Bates, L.C., Zieff, G., Stanford, K., Moore, J.B., Kerr, Z.Y., Hanson, E.D., . . . Stoner, L. (2020). COVID-19 Impact on behaviors across the 24-hour day in children and adolescents: Physical activity, sedentary behavior, and sleep. Children, 7(9), 138. doi:10.3390/children7090138

Brusseau, T.A., Hannon, J., \& Burns, R. (2016). The effect of a comprehensive school physical activity program on physical activity and health-related fitness in children from low-income families. Journal of Physical Activity and Health, 13(8), 888-894. PubMed ID: 27144329 doi:10.1123/jpah.2016-0028

Carson, R., \& Webster, C.A. (Eds.). (2019). Comprehensive school physical activity programs: Putting evidence-based research into practice. Champaign, IL: Human Kinetics.

Centeio, E.E., McCaughtry, N., Gutuskey, L., Garn, A.C., Somers, C., Shen, B., . . Kulik, N.L. (2014). Physical activity change through comprehensive school physical activity programs in urban elementary schools. Journal of Teaching in Physical Education, 33(4), 573591. doi:10.1123/jtpe.2014-0067

Centeio, E.E., Somers, C., Moore, E.W.G., Kulik, N., Garn, A., \& McCaughtry, N. (2021). Effects of a comprehensive school health program on elementary student academic achievement. Journal of School Health, 91(3), 239-249. doi:10.1111/josh.12994

Centers for Disease Control and Prevention. (2019). Increasing physical education and physical activity: A framework for schools. Retrieved from https://www.cdc.gov/healthyschools/physicalactivity/pdf/2019_ 04_25_PE-PA-Framework_508tagged.pdf

Cipriani, K., Richardson, C., \& Roberts, G. (2012). Family and community involvement in the comprehensive school physical activity program. Journal of Physical Education, Recreation \& Dance, 83(7), 20-26. doi:10.1080/07303084.2012.10598807

Duncan S., Duncan T.E., \& Strycker L.A. (2005). Sources and types of social support in youth physical activity. Health Psychology, 24(1), 3-10. PubMed ID: 15631557 doi:10.1037/0278-6133.24.1.3

Dunton, G.F., Do, B., \& Wang, S.D. (2020). Early effects of the COVID19 pandemic on physical activity and sedentary behavior in children living in the US. BMC Public Health, 20(1), 1-13. doi:10.1186/ s12889-020-09429-3

Edwardson, C.L., \& Gorely, T. (2010). Parental influences on different types and intensities of physical activity in youth: A systematic review. Psychology of Sport and exercise, 11(6), 522-535. doi:10. 1016/j.psychsport.2010.05.001

Erwin, H., Beighle, A., Carson, R.L., \& Castelli, D.M. (2013). Comprehensive school-based physical activity promotion: A review. Quest, 65(4), 412-428. doi:10.1080/00336297.2013.791872

Garn, A., Centeio, E., Shen, B., Martin, J., \& McCaughtry, N. (2016). A moderated mediation analysis of children's physical activity enjoyment. The Journal of Positive Psychology, 11(4), 428-438. doi:10. 1080/17439760.2015.1092568

Gilic, B., Ostojic, L., Corluka, M., Volaric, T., \& Sekulic, D. (2020). Contextualizing parental/familial influence on physical activity in Adolescents before and during COVID-19 pandemic: A prospective analysis. Children, 7(9), 125. doi:10.3390/children7090125

Hall, G., Laddu, D.R., Phillips, S.A., Lavie, C.J., \& Arena, R. (2020). A tale of two pandemics: How will COVID-19 and global trends in physical inactivity and sedentary behavior affect one another? Progress in Cardiovascular Diseases, 64, 108-110. PubMed ID: 32277997 doi:10.1016/j.pcad.2020.04.005

Hunt, K., \& Metzler, M. (2017). Adoption of comprehensive school physical activity programs: A literature review. Physical Educator, 74(2), 315. doi:10.18666/TPE-2017-V74-I2-7167

Iqbal, S.A., \& Tayyab, N. (2021). COVID-19 and children: The mental and physical reverberations of the pandemic. Child: Care, Health and Development, 47(1), 136-139. doi:10.1111/cch.12822 
Kelder, S.H., Karp, G.G., Scruggs, P.W., \& Brown, H. (2014). Setting the stage: Coordinated approaches to school health and physical education. Journal of Teaching in Physical Education, 33(4), 440-448. doi:10.1123/jtpe.2014-0087

Michigan Department of Education. (2017). K-12 physical education standards. Retrieved from https://www.google.com/url? $\mathrm{sa}=\mathrm{t} \& \mathrm{rct}=\mathrm{j} \& \mathrm{q}=\&$ esrc $=\mathrm{s} \&$ source $=$ web $\& \mathrm{~cd}=\& \mathrm{ved}=2 \mathrm{ahUKEwj} 54 \mathrm{qW}$ 58tXvAhVoCTQIHcOaA2kQFjAAegQIAxAD\&url=https\%3A\%2F \%2Fwww.michigan.gov\%2Fdocuments\%2Fmde\%2FK_12_PE_ Standards_Aug_17_ADA_compliance9-18_601116_7.pdf\&usg= AOvVaw325yYp8PsUlic5ZDF1rz1L

Munasinghe, S., Sperandei, S., Freebairn, L., Conroy, E., Jani, H., Marjanovic, S., \& Page, A. (2020). The impact of physical distancing policies during the COVID-19 pandemic on health and well-being among Australian adolescents. Journal of Adolescent Health, 67(5), 653-661. doi:10.1016/j.jadohealth.2020.08.008

Ortega, A.N., Albert, S.L., Chan-Golston, A.M., Langellier, B.A., Glik, D.C., Belin, T.R., . . Prelip, M. L. (2016). Substantial improvements not seen in health behaviors following corner store conversions in two Latino food swamps. BMC Public Health, 16(1), 1-10. doi:10.1186/ s12889-016-3074-1

Pavlovic, A., DeFina, L.F., Natale, B.L., Thiele, S.E., Walker, T.J., Craig, D.W., . . . Kohl, H.W., III. (2021). Keeping children healthy during and after COVID-19 pandemic: Meeting youth physical activity needs. BMC Public Health, 21(1), 1-8.

Perez, D., Thalken, J.K., Ughelu, N.E., Knight, C.J., \& Massey, W. (2021). Nowhere to go: Parents' descriptions of children's physical activity during a global pandemic. Frontiers in Public Health, 9, 1-8.

Schwarzer, R., Schüz, B., Ziegelmann, J.P., Lippke, S., Luszczynska, A., \& Scholz, U. (2007). Adoption and maintenance of four health behaviors: Theory-guided longitudinal studies on dental flossing, seat belt use, dietary behavior, and physical activity. Annals of Behavioral Medicine, 33,(2) 156. PubMed ID: 17447868 doi:10.1007/BF02879897

SHAPE. (2020). National physical education standards-SHAPE America sets the standards. Retrieved from https://www.shapeamerica.org/ standards/pe/

Sirard, J.R., Hannan, P., Cutler, G.J., \& Nuemark-Sztainer, D. (2013). Evaluation of 2 self-report measures of physical activity with accelerometry in young adults. Journal of Physical Activity and Health, 10(1), 85-96. PubMed ID: 22241145 doi:10.1123/jpah.10.1.85

Thiagarajah, K., Fly, A.D., Hoelscher, D.M., Bai, Y., Lo, K., Leone, A., \& Shertzer, J.A. (2008). Validating the food behavior questions from the elementary school SPAN questionnaire. Journal of Nutrition Education and Behavior, 40(5), 305-310. PubMed ID: 18725149 doi:10. 1016/j.jneb.2007.07.004

United Nations Educational, Scientific and Cultural Organization. (2020, March 26). UNESCO rallies international organizations, civil society and private sector partners in a broad coalition to ensure \#Learning Never Stops. Retrieved from https://en.unesco.org/news/unescorallies-international-organizations-civil-society-and-private-sectorpartners-broad

U.S. Department of Health and Human Services. (2019). Youth risk behavior surveillance system.

United States Department of Health and Human Services and U.S. Department of Agriculture. (2015). 2015-2020 Dietary Guidelines for Americans (8th ed.). Retrieved from https://health.gov/our-work/ food-nutrition/previous-dietary-guidelines/2015

Xiang, P., McBride, R.E., Guan, J., \& Solmon, M.A. (2003). Children's motivation in elementary physical education: An expectancy-value model of achievement choice. Research Quarterly for Exercise and Sport, 74(1), 25-35. PubMed ID: 12659473 doi:10.1080/02701367. 2003.10609061 